\title{
Genetic Background of Immune Complications after Allogeneic Hematopoietic Stem Cell Transplantation in Children
}

\author{
Szymon Skoczen, ${ }^{1}$ Miroslaw Bik-Multanowski, ${ }^{2}$ Jacek J. Pietrzyk, \\ Agnieszka Grabowska, ${ }^{2}$ Kamil Fijorek, ${ }^{3}$ Wojciech Strojny, ${ }^{4}$ Kinga Klus-Kwiecinska, ${ }^{4}$ \\ Walentyna Balwierz, ${ }^{4}$ and Maciej Siedlar ${ }^{1}$ \\ ${ }^{1}$ Department of Clinical Immunology, Chair of Clinical Immunology and Transplantation, Institute of Pediatrics, \\ Jagiellonian University Medical College, Wielicka Street 265, 30-663 Krakow, Poland \\ ${ }^{2}$ Department of Medical Genetics, Institute of Pediatrics, Jagiellonian University Medical College, Krakow, Poland \\ ${ }^{3}$ Department of Statistics, Cracow University of Economics, Rakowicka Street 27, 31-510 Krakow, Poland \\ ${ }^{4}$ Department of Oncology and Hematology, Institute of Pediatrics, Jagiellonian University Medical College, Krakow, Poland
}

Correspondence should be addressed to Szymon Skoczen; szymon.skoczen@uj.edu.pl

Received 15 October 2015; Accepted 9 November 2015

Academic Editor: Ciprian Tomuleasa

Copyright ( 2016 Szymon Skoczen et al. This is an open access article distributed under the Creative Commons Attribution License, which permits unrestricted use, distribution, and reproduction in any medium, provided the original work is properly cited.

Immune reactions are among the most serious complications observed after hematopoietic stem cell transplantation (HSCT) in children. Microarray technique allows for simultaneous assessment of expression of nearly all human genes. The objective of the study was to compare the whole genome expression in children before and after HSCT. A total of 33 children referred for HSCT were enrolled in the study. In 70\% of the patients HSCT was performed for the treatment of neoplasms. Blood samples were obtained before HSCT and six months after the procedure. Subsequently, the whole genome expression was assessed in leukocytes using GeneChip Human Gene 1.0 ST microarray. The analysis of genomic profiles before and after HSCT revealed altered expression of 124 genes. Pathway enrichment analysis revealed upregulation of five pathways after HSCT: allograft rejection, graft-versus-host disease, type I diabetes mellitus, autoimmune thyroid disease, and viral myocarditis. The activation of those pathways seems to be related to immune reactions commonly observed after HSCT. Our results contribute to better understanding of the genomic background of the immunologic complications of HSCT.

\section{Introduction}

Allogeneic hematopoietic stem cell transplantation (HSCT) has progressed from a risky experimental therapy to a safe and life-saving treatment modality in a relatively short span of five decades [1]. However, transplant recipients still require prolonged treatment with multiple, nonspecific, and toxic immunosuppressive drugs and are at a constant risk of immune reactions which may lead to graft-versus-host disease (GvHD) or graft rejection (GR). Immune reactions result from the activation of donor lymphocytes with subsequent recognition of the host's antigens, emergence of effector $\mathrm{T}$ cells, production of alloantibodies, and infiltration of tissues by alloreactive cells [2].
The aim of the study was to analyze the spectrum of alterations of genome expression resulting from HSCT.

\section{Materials and Methods}

This was a prospective study conducted from May 2009 to September 2012. The study group consisted of children and teenagers referred for HSCT, which was performed according to disease-specific treatment protocols. The study was approved by the Ethics Committee of the Jagiellonian University (KBET/96/B/2008). Written informed consent was obtained from all parents and from all patients $\geq 16$ years of age. 
TABLE 1: The indications for HSCT (pre-HSCT group).

\begin{tabular}{lc}
\hline Condition & $n(\%)$ \\
\hline Acute lymphoblastic leukemia (ALL) & $15(36)$ \\
Acute myeloblastic leukemia (AML) & $5(15)$ \\
Acute bilineage leukemia (ABL) & $1(3)$ \\
Juvenile myelomonocytic and acute myeloblastic & $1(3)$ \\
leukemia (JMML/AML) & $1(3)$ \\
Myelodysplastic syndrome (MDS) & $23(70)$ \\
Neoplasms (total) & $4(12)$ \\
Severe aplastic anemia (SAA) & $3(9)$ \\
Chronic granulomatous disease (CGD) & $1(3)$ \\
Autoimmune lymphoproliferative syndrome (ALPS) & $1(3)$ \\
Hyper-IgM syndrome (HIgM) & $1(3)$ \\
Inherited neutropenia (IN) & $10(30)$ \\
Nonneoplastic conditions (total)
\end{tabular}

2.1. Microarray Analysis. Blood samples $(1.5 \mathrm{~mL})$ were collected from each patient before conditioning and approximately six months after HSCT (median 6.3 months). We assessed the whole genome expression in peripheral blood leukocytes using GeneChip Human Gene 1.0 ST Array (Affymetrix, Santa Clara, USA). Total RNA extraction was performed using RiboPure Blood Kit (Ambion, Life Technologies, Carlsbad, USA). Whole transcript microarray experiment was performed according to the manufacturer's protocol (GeneChip Whole Transcript Sense Target Labeling Assay Manual, Version 4).

2.2. Statistical Analysis. Study sample size ensures adequate power to detect a 1.5 -fold change. The microarray data were preprocessed using the R/Bioconductor package [3-5]. Robust Multiarray Average (RMA) was used for normalization [6]. Quality control was performed by investigating Principal Component Analysis (PCA), Relative Log Expression (RLE), and Normalized Unscaled Standard Error (NUSE) plots.

Moderated $t$-tests [7] were performed to detect the probes that were differentially expressed between groups, using the limma package [8] in the $\mathrm{R}$ statistical software. It was assumed that the $\log _{2}$ transformed gene expression levels are normally distributed and the between-group variation is of comparable magnitude. Multiple testing correction (Benjamini-Hochberg procedure) was applied to control the false discovery rate (FDR) [9]. Significantly different expression in the probe sets was defined as multiple comparisoncorrected two-sided $p$ value $<0.05$.

DAVID annotation tools were used to compare gene set enrichment between the groups $[10,11]$. The KEGG (Kyoto Encyclopedia of Genes and Genomes; http://www.genome .jp/kegg/) and Biocarta (http://www.biocarta.com/) pathways were selected for analysis. A set of top 250 differentially expressed genes (TOP 250 database) was exported for pathway enrichment analysis.
TABLE 2: Characteristics of studied groups.

\begin{tabular}{|c|c|}
\hline \multicolumn{2}{|c|}{ Pre-HSCT group } \\
\hline$N$ & 33 \\
\hline Sex & Boys 25 , girls 8 \\
\hline Age (years) & $1.5-19$ (median 10.5$)$ \\
\hline Chemotherapy before HSCT (\%) & $23(71 \%)$ \\
\hline First line & 13 \\
\hline Second line & 9 \\
\hline$\geq$ third line & 1 \\
\hline Local radiotherapy & 7 \\
\hline Cranial (dose) & 5 (12 Gy-4, 18 Gy-1) \\
\hline Testes (dose) & 2 (12 Gy/24 Gy, 18 Gy/18 Gy) \\
\hline $\begin{array}{l}\text { Time since diagnosis and patient } \\
\text { selection (years) }\end{array}$ & Median, 1.4 ; range $0.08-12.9$ \\
\hline \multicolumn{2}{|c|}{ Post-HSCT group } \\
\hline$N$ & 20 \\
\hline Sex & Boys 14 , girls 7 \\
\hline Age (years) & 2.8-19.5 (median 9.6) \\
\hline $\begin{array}{l}\text { Conditioning regimen based on } \\
\text { busulfan }(n)\end{array}$ & $9(45 \%)$ \\
\hline $\begin{array}{l}\text { Total body irradiation, } 12 \text { Gy/ } 6 \\
\text { fractions }(n)\end{array}$ & $6(30 \%)$ \\
\hline \multicolumn{2}{|l|}{ GvHD prophylaxis $(n)$} \\
\hline Ciclosporin & $2(10 \%)$ \\
\hline Methotrexate + ciclosporin & $18(90 \%)$ \\
\hline $\operatorname{GvHD}(n)$ & $14(70 \%)$ \\
\hline $\begin{array}{l}\text { Median time from HSCT to the } \\
\text { second assessment (range) }\end{array}$ & $6.4(6-13)$ months \\
\hline Systemic glucocorticoids (\%) & $16(80 \%)$ \\
\hline $\begin{array}{l}\text { Median and range of cumulative } \\
\text { dose of glucocorticoids } \\
\text { (equivalent of prednisone) }\end{array}$ & $1463(29-9758) \mathrm{mg} / \mathrm{m}^{2}$ \\
\hline $\begin{array}{l}\text { Median duration of systemic } \\
\text { glucocorticoids therapy }\end{array}$ & 105 (3-240) days \\
\hline $\begin{array}{l}\text { Median time since } \\
\text { discontinuation of } \\
\text { glucocorticoids (range) }\end{array}$ & $3.5(0.4-14.3)$ months \\
\hline $\begin{array}{l}\text { Median time from } \\
\text { discontinuation of } \\
\text { immunosuppressive treatment to } \\
\text { the second assessment (range) } \\
\text { (16 patients) }\end{array}$ & $1.8(0-9)$ months \\
\hline
\end{tabular}

\section{Results}

3.1. Characteristic of the Study Group. The group of patients assessed before HSCT (pre-HSCT group) included 33 patients aged 1.5-19 (median 10.5) years, referred to the Stem Cell Transplantation Centre of the University Children's Hospital in Krakow. The indications for HSCT are listed in Table 1. Characteristics of children referred for HSCT are presented in Table 2.

The group of patients assessed after HSCT (post-HSCT group) included 20 children from the pre-HSCT group, aged 2.8-19.5 (median 9.6) years. In six patients in the preHSCT group the results of the microarray analysis were 
TABLE 3: Summary of the number of differentially expressed genes between studied groups.

\begin{tabular}{|c|c|c|c|}
\hline \multirow{2}{*}{ Study groups } & \multirow{2}{*}{$\begin{array}{c}\text { Genes with significant differences revealed after } \\
\text { Benjamini-Hochberg correction }\end{array}$} & \multicolumn{2}{|c|}{ Number of genes with expression fold change $\geq 1.5$} \\
\hline & & +1.5 & -1.5 \\
\hline Post-HSCT/pre-HSCT & $\begin{array}{c}13 \\
\text { Fold change } \\
+1.5-0 \\
-1.5-1\end{array}$ & 44 & 80 \\
\hline
\end{tabular}

not reliable for technical reasons (poor quality of RNA sample) and another three patients were lost to follow-up. Four children died due to complications of treatment or disease progression. All patients in the post-HSCT group were treated with ablative conditioning regiments. The key clinical characteristics of the post-HSCT group are presented in Table 2.

3.2. Whole Genome Expression. All the primary microarray data were submitted to GEO public repository and are accessible using GEO Series accession number GSE69421 (http://www.ncbi.nlm.nih.gov/geo/query/acc.cgi?acc=GSE32472).

A summary of the differentially expressed genes is presented in Table 3.

A comparison of the pre-HSCT group and post-HSCT group revealed 124 genes with difference in expression and fold change $\geq 1.5$. For $36 \%$ of these genes the expression was higher in the post-HSCT group (Table 3).

3.3. Pathway Enrichment Analysis. Based on the results presented in Table 4, pathway enrichment analysis was performed.

The genes showing overexpression in the post-HSCT group compared with the pre-HSCT group formed pathways responsible for donor/recipient alloaggression, including "allograft rejection" and "graft-versus-host disease," which represent the most common complications of HSCT as well as pathways representing immunologic reaction against specific organs ("type I diabetes mellitus," "autoimmune thyroid disease," and "viral myocarditis"), which are among the late complications of HSCT. At the same time parallel activation of genes forming "antigen processing and presentation" pathway was observed.

The genes showing underexpression in the post-HSCT group compared with the pre-HSCT group represent pathways regulating erythropoiesis and metabolism of proteins. As analysis was performed after intensive proliferation due to reconstitution of hematopoiesis, inhibition of these genes might have occurred. The pathway "Th1/Th2 Differentiation" could be inhibited as a result of prolonged immunosuppressive treatment used for GvHD prevention in most patients treated with HSCT.

\section{Discussion}

Acute graft-versus-host disease (aGvHD) is the leading cause of morbidity and mortality after HSCT that affects the skin, liver, and gastrointestinal tract and contributes to transplantrelated morbidity and mortality [2]. Approximately 50\% of patients treated with HSCT subsequently develop aGvHD and require systemic treatment [12]. Chronic graft-versushost disease (cGvHD) occurs in $40 \%$ of patients treated with HSCT from an HLA-identical sibling and in more than $50 \%$ of patients treated with HSCT from an HLAnonidentical related donor and in $70 \%$ of patients treated with HSCT from an HLA-matched unrelated donor. The onset of symptoms is within a median of 133 days after an unrelated donor HSCT [13]. cGvHD is an immunoregulatory disorder occurring after allogeneic HSCT and has clinical features of both autoimmune disorder and immunodeficiency. The features of cGvHD resemble other autoimmune diseases such as Sjögren syndrome, scleroderma, primary biliary cirrhosis, and immune cytopenia [14]. Graft rejection (GR) occurs in $12 \%$ of children undergoing allogeneic HSCT within a median of 63 days after the transplantation [15]. Our study revealed that the genes showing overexpression in the postHSCT group compared with the pre-HSCT group formed the pathways responsible for "allograft rejection" and "graftversus-host disease" thus giving genetic background for the observed immune reactions. Even though no case of GR was observed in the study group, the activation of the genes responsible for GR is obvious, and our results suggest the effectiveness of the preventive treatment used in these patients.

The microarray analysis indicated presence of three other pathways: "type I diabetes mellitus," "autoimmune thyroid disease," and "viral myocarditis." The incidence of compensated hypothyroidism in patients after HSCT ranges from 25 to $30 \%$ with a median latency of 2 years; overt hypothyroidism is diagnosed in up to $9 \%$ of patients with a latency of 2.7 years. Younger age is associated with higher risk of hypothyroidism $[16,17]$. Patients treated with HSCT also have 2.3- to 4.0-fold higher risk of death due to cardiac causes compared with the general population $[18,19]$. The cumulative incidence of cardiovascular diseases approaches $23 \%$ at 25 years after HSCT and is highest among the allogeneic HSCT recipients. The incidence appears to increase with time $[20,21]$. Moreover, the patients treated with HSCT are known to have an increased risk of diabetes mellitus [22]. The risk of diabetes adjusted for age, sex, race, and BMI is 3.7 times higher in patients after allogeneic HSCT compared with the general population [23].

Activated $\mathrm{T}$ cells play additional important role in controlling a variety of critical steps after HSCT, such as facilitating engraftment of hematopoietic stem cells, immune reconstitution, and elimination of residual disease, but they 


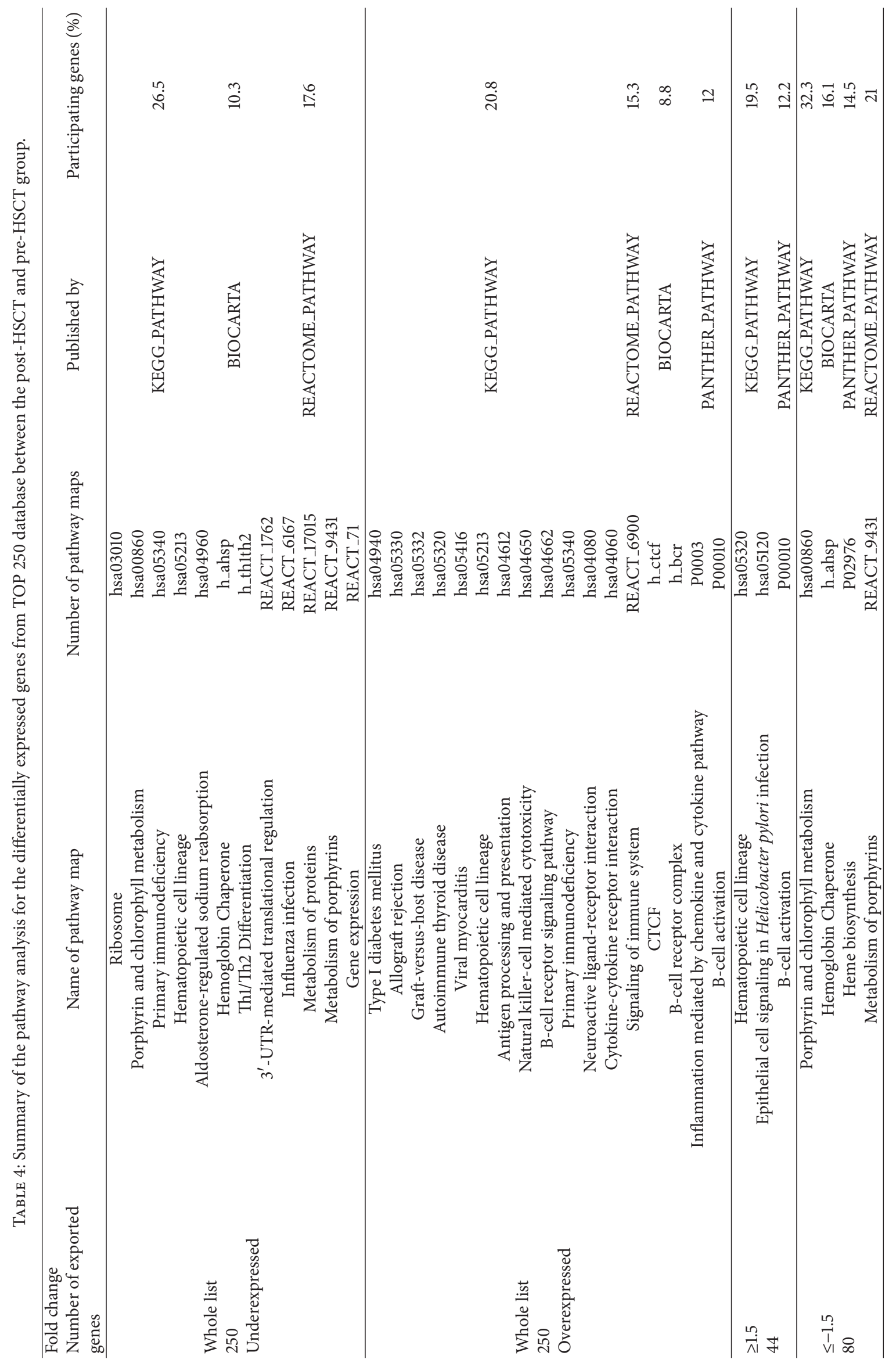


are also responsible for immune reactions against the host's tissues $[24,25]$. Our data support the hypothesis on the role of activation of gene machinery resulting in aggression of donor immune system against specific host organs leading to deterioration of their function. Regulatory $\mathrm{T}$ cells have been shown to mitigate immune reactions after HSCT by suppressing the early expansion of donor $\mathrm{T}$ cells [26].

So far, there is no validated diagnostic or predictive blood biomarker for GvHD which could improve diagnosis and prognosis and help to guide therapeutic interventions $[26,27]$. Currently, the diagnosis of GvHD is based on clinical manifestations in one or more of the main target organs and on biopsy results. Moreover, once GvHD occurs, the most important predictor of long-term survival is the primary response to therapy. In patients who are resistant to initial therapy, the risk of morbidity and mortality increases significantly $[28,29]$. Thus, there is a need to identify new biomarkers to predict not only GvHD development but also the survival and treatment outcomes of GvHD. Future studies might answer the question whether specific gene expression patterns can be used as biomarkers of immune complications after HSCT.

In conclusion, the results of our whole genome expression study revealed altered expression of the genes responsible for immune reactions against recipient/donor cells, proving genetic background for one of the most common complications (GvHD, GR), observed after HSCT.

\section{Conflict of Interests}

The authors declare that there is no conflict of interests regarding the publication of this paper.

\section{Authors' Contribution}

Szymon Skoczen designed and performed research, analyzed and interpreted data, and wrote the paper. Miroslaw BikMultanowski performed research and analyzed and interpreted data. Agnieszka Grabowska and Kamil Fijorek performed research and collected data. Wojciech Strojny and Kinga Klus-Kwiecinska analyzed and interpreted data. Jacek J. Pietrzyk, Walentyna Balwierz, and Maciej Siedlar conducted the clinical protocols and interpreted data.

\section{Acknowledgment}

This work was supported by national Grant no. NN 407 198737.

\section{References}

[1] E. D. Thomas, H. L. Lochate Jr., W. C. Lu, and J. W. Ferrebee, "Intravenous infusion of bone marrow in patients receiving radiation and chemotherapy," The New England Journal of Medicine, vol. 257, no. 11, pp. 491-496, 1957.

[2] J. L. Ferrara, J. E. Levine, P. Reddy, and E. Holler, "Graft-versushost disease," The Lancet, vol. 373, no. 9674, pp. 1550-1561, 2009.

[3] M. T. Lee, "Power and sample size considerations," in Analysis of Microarray Expression Data, pp. 191-236, Kluwer Academic Publishers, Boston, Mass, USA, 2004.
[4] R. C. Gentleman, V. J. Carey, D. M. Bates et al., "Bioconductor: open software development for computational biology and bioinformatics," Genome Biology, vol. 5, no. 10, article R80, 2004.

[5] H. Bengtsson, K. Simpson, J. Bullard, and K. Hansen, "Aroma .affymetrix: a generic framework in $\mathrm{R}$ for analyzing small to very large Affymetrix data sets in bounded memory," Tech. Rep. 745, Department of Statistics, University of California, Berkeley, Calif, USA, 2004.

[6] R. A. Irizarry, B. Hobbs, F. Collin et al., "Exploration, normalization, and summaries of high density oligonucleotide array probe level data," Biostatistics, vol. 4, no. 2, pp. 249-264, 2003.

[7] G. K. Smyth, "Linear models and empirical Bayes methods for assessing differential expression in microarray experiments," Statistical Applications in Genetics and Molecular Biology, vol. 3, no. 1, pp. 1-25, 2004.

[8] G. K. Smyth, "Limma: linear models for microarray data," in Bioinformatics and Computational Biology Solutions Using R and Bioconductor, R. Gentleman, V. Carey, S. Dudoit, R. Irizarry, and W. Huber, Eds., Statistics for Biology and Health, pp. 397-420, Springer, New York, NY, USA, 2005.

[9] Y. Benjamini and Y. Hochberg, "Controlling the false discovery rate: a practical and powerful approach to multiple testing," Journal of the Royal Statistical Society: Series B (Statistical Methodology), vol. 57, pp. 289-300, 1995.

[10] D. W. Huang, B. T. Sherman, and R. A. Lempicki, "Systematic and integrative analysis of large gene lists using DAVID bioinformatics resources," Nature Protocols, vol. 4, no. 1, pp. 44-57, 2009.

[11] D. W. Huang, B. T. Sherman, and R. A. Lempicki, "Bioinformatics enrichment tools: paths toward the comprehensive functional analysis of large gene lists," Nucleic Acids Research, vol. 37, no. 1, pp. 1-13, 2009.

[12] B. R. Blazar, W. J. Murphy, and M. Abedi, "Advances in graft-versus-host disease biology and therapy," Nature Reviews Immunology, vol. 12, no. 6, pp. 443-458, 2012.

[13] K. M. Sullivan, E. Agura, C. Anasetti et al., "Chronic graftversus-host disease and other late complications of bone marrow transplantation," Seminars in Hematology, vol. 28, no. 3, pp. 250-259, 1991.

[14] A. Shimabukuro-Vornhagen, M. J. Hallek, R. F. Storb, and M. S. von Bergwelt-Baildon, "The role of B cells in the pathogenesis of graft-versus-host disease," Blood, vol. 114, no. 24, pp. 4919-4927, 2009.

[15] S. Breuer, S. Preuner, G. Fritsch et al., "Early recipient chimerism testing in the T- and NK-cell lineages for risk assessment of graft rejection in pediatric patients undergoing allogeneic stem cell transplantation," Leukemia, vol. 26, no. 3, pp. 509-519, 2012.

[16] C. Berger, B. Le-Gallo, J. Donadieu et al., "Late thyroid toxicity in 153 long-term survivors of allogeneic bone marrow transplantation for acute lymphoblastic leukaemia," Bone Marrow Transplantation, vol. 35, no. 10, pp. 991-995, 2005.

[17] H. Ishiguro, Y. Yasuda, Y. Tomita et al., "Long-term followup of thyroid function in patients who received bone marrow transplantation during childhood and adolescence," The Journal of Clinical Endocrinology \& Metabolism, vol. 89, no. 12, pp. 59815986, 2004.

[18] S. Bhatia, L. Francisco, A. Carter et al., "Late mortality after allogeneic hematopoietic cell transplantation and functional status of long-term survivors: report from the Bone Marrow Transplant Survivor Study," Blood, vol. 110, no. 10, pp. 37843792, 2007. 
[19] N. S. Majhail, K. K. Ness, L. J. Burns et al., "Late effects in survivors of Hodgkin and non-Hodgkin lymphoma treated with autologous hematopoietic cell transplantation: a report from the bone marrow transplant survivor study," Biology of Blood and Marrow Transplantation, vol. 13, no. 10, pp. 1153-1159, 2007.

[20] P. W. F. Wilson, R. B. D’Agostino, D. Levy, A. M. Belanger, H. Silbershatz, and W. B. Kannel, "Prediction of coronary heart disease using risk factor categories," Circulation, vol. 97, no. 18, pp. 1837-1847, 1998.

[21] S. M. Grundy, R. Pasternak, P. Greenland, S. Smith Jr., and V. Fuster, "AHA/ACC scientific statement: assessment of cardiovascular risk by use of multiple-risk-factor assessment equations: a statement for healthcare professionals from the American Heart Association and the American College of Cardiology," Journal of the American College of Cardiology, vol. 34, no. 4, pp. 1348-1359, 1999.

[22] S. Bhatia, "Long-term health impacts of hematopoietic stem cell transplantation in form recommendations for follow-up," Expert Review of Hematology, vol. 4, pp. 437-452, 2011.

[23] K. S. Baker, K. K. Ness, J. Steinberger et al., "Diabetes, hypertension, and cardiovascular events in survivors of hematopoietic cell transplantation: a report from the bone marrow transplantation survivor study," Blood, vol. 109, no. 4, pp. 1765-1772, 2007.

[24] R. E. Curtis, L. B. Travis, P. A. Rowlings et al., "Risk of lymphoproliferative disorders after bone marrow transplantation: a multi-institutional study," Blood, vol. 94, no. 7, pp. 2208-2216, 1999.

[25] F. Ayuk, A. Shimoni, A. Nagler et al., "Efficacy and toxicity of low-dose escalating donor lymphocyte infusion given after reduced intensity conditioning allograft for multiple myeloma," Leukemia, vol. 18, no. 3, pp. 659-662, 2004.

[26] M. Edinger, P. Hoffmann, J. Ermann et al., "CD $4^{+} \mathrm{CD} 25^{+}$ regulatory $\mathrm{T}$ cells preserve graft-versus-tumor activity while inhibiting graft-versus-host disease after bone marrow transplantation," Nature Medicine, vol. 9, no. 9, pp. 1144-1150, 2003.

[27] S. Paczesny, "Discovery and validation of graft versus-host disease biomarkers," Blood, vol. 121, no. 4, pp. 585-594, 2013.

[28] M. T. Van Lint, G. Milone, S. Leotta et al., "Treatment of acute graft-versus-host disease with prednisolone: significant survival advantage for day +5 responders and no advantage for nonresponders receiving anti-thymocyte globulin," Blood, vol. 107, no. 10, pp. 4177-4181, 2006.

[29] H. J. Deeg, "How I treat refractory acute GVHD," Blood, vol. 109, no. 10, pp. 4119-4126, 2007. 

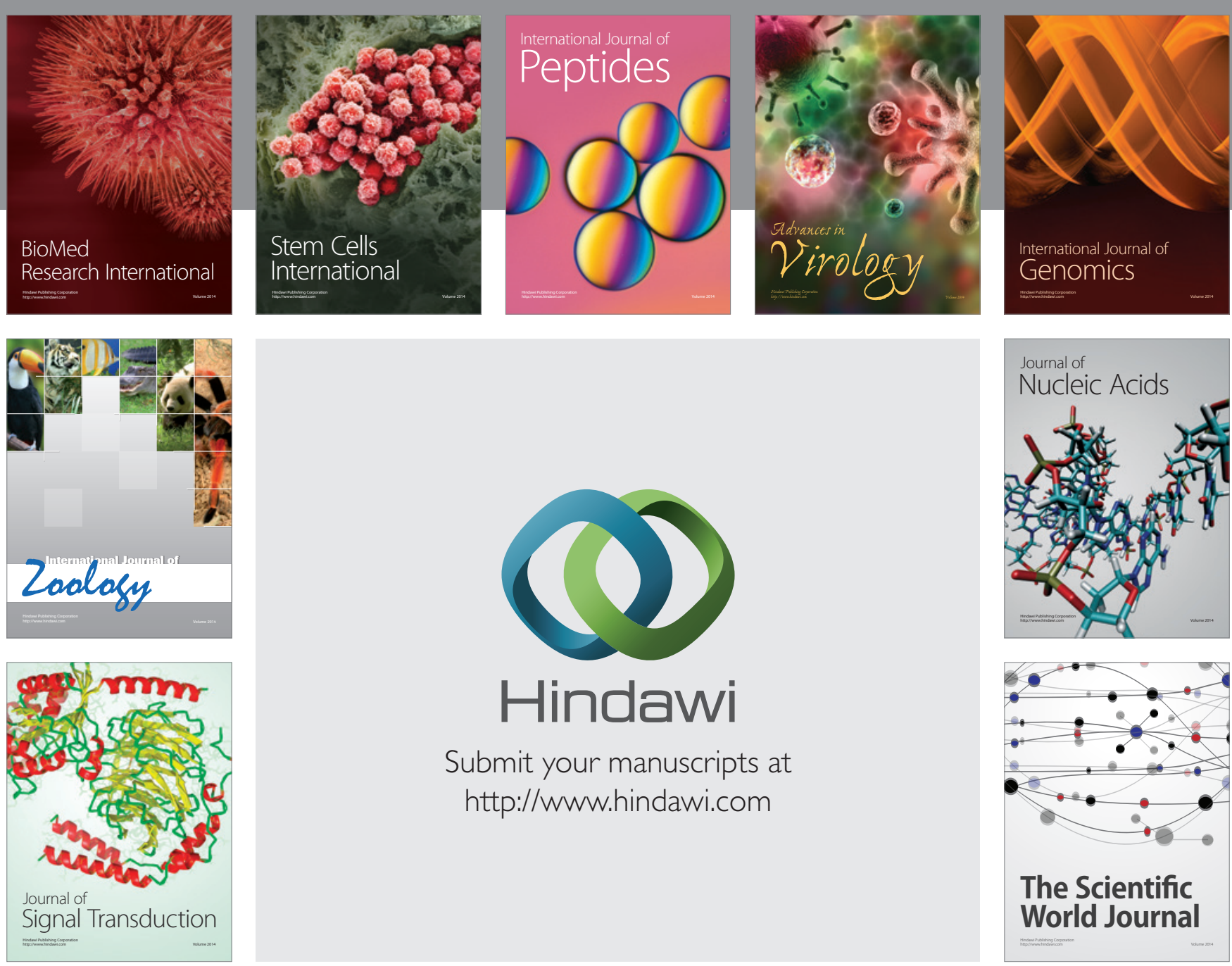

Submit your manuscripts at

http://www.hindawi.com
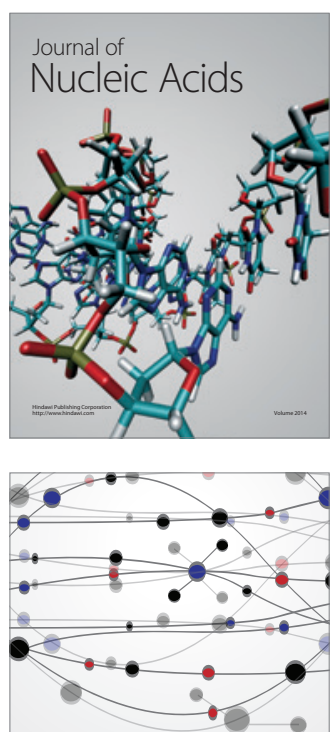

The Scientific World Journal
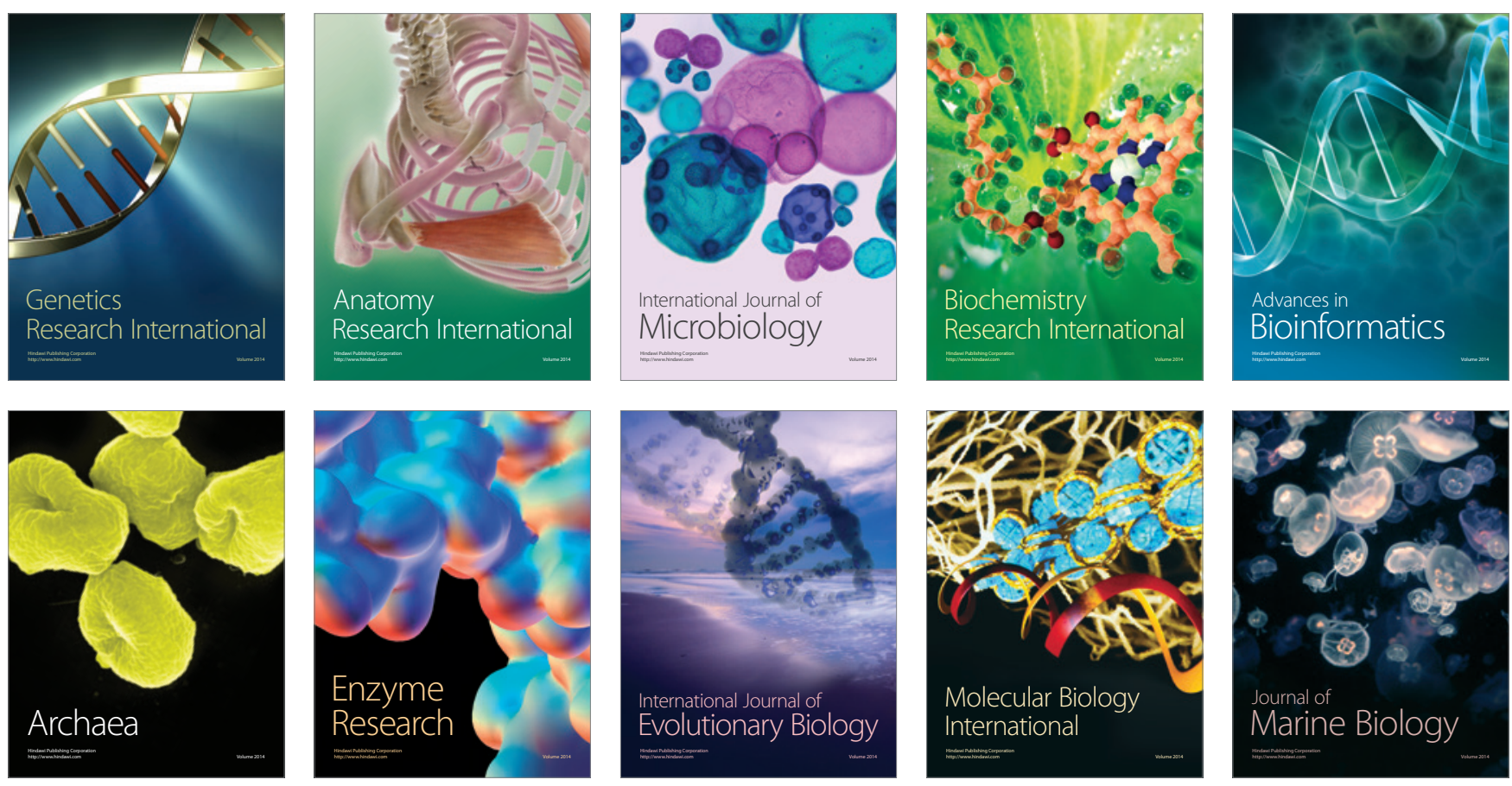